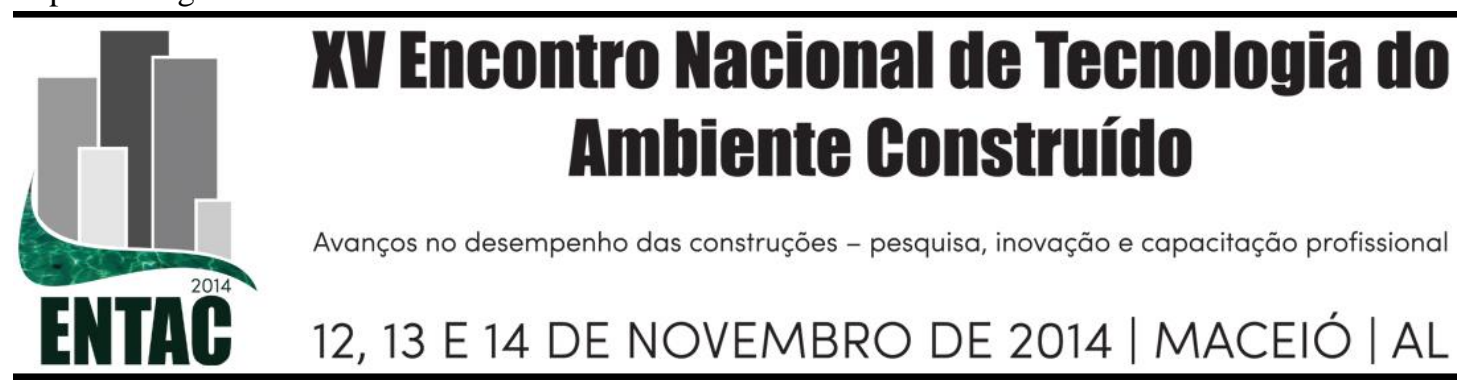

\title{
INSTRUMENTOS TRIDIMENSIONAIS DE AVALIAÇÃO DE QUALIDADE DE PROJETO DO PONTO DE VISTA DAS SAÍDAS DE EMERGÊNCIA EM EDIFICAÇÕES COMPLEXAS
}

\section{ONO, Rosaria (1); MOREIRA, Katia Beatris Rovaron (2); LEIVAS, Tomaz Puga \\ (3); CAMANHO, Gilberto Luis (4)}

(1) Faculdade de Arquitetura e Urbanismo da Universidade de São Paulo, e-mail: rosaria@usp.br; (2) Faculdade de Arquitetura e Urbanismo da Universidade de São Paulo, e-mail: katiabeatris@uolcom.br;

(3) Instituto de Ortopedia e Traumatologia do Hospital das Clínicas/ Faculdade de Medicina da

Universidade de São Paulo, e-mail: tomaz.puga@hc.fm.usp.br; (4) Departamento de Ortopedia e Traumatologia da Faculdade de Medicina da Universidade de São Paulo, e-mail:

gilbertocamanho@uol.com.br

\begin{abstract}
RESUMO
O objetivo deste trabalho é apresentar alguns dos resultados da pesquisa em andamento, cuja finalidade é discutir a efetividade de instrumentos "tridimensionais" de análise de wayfinding na avaliação da qualidade do projeto de saídas de emergência. Foram propostos procedimentos para realização de uma pesquisa experimental exploratória, em um edifício em uso, com espaços internos de circulação considerados complexos - no caso, um edifício hospitalar. A coleta de dados desta pesquisa exploratória foi realizada por meio de dois instrumentos, a saber: a) gravação de imagem por câmera digital fixada junto ao corpo do sujeito que caminha pelo edifício até atingir pontos pré-estabelecidos; b) preenchimento de questionário ao final dos percursos experimentados pelos sujeitos. Os experimentos possibilitaram uma avaliação efetiva dos instrumentos utilizados e a proposição de aprimoramentos que permitirão a sua aplicação e a reprodução numa escala maior, na pesquisa para verificação da qualidade do projeto de saídas de emergência.
\end{abstract}

Palavras-chave: Saídas de emergência, Wayfinding, Comportamento humano.

\begin{abstract}
The objective of this paper is to present the results of a research concerning the validity of tridimensional tools for the evaluation of wayfinding and its effectiveness in fire exits design. Several procedures were proposed in order to carry out an exploratory research experiment in an existing building, considering a complex building such as a health-care facility. The data collection was done by the adoption of two tools: a) a recording of the subjects' movements through the building by a digital videocamera and b) $a$ survey based on a questionnaire fulfilled by the subjects in two phases. The experiments allowed the effective evaluation of these tools and the proposition of improvements in order to carry out a full-scale experiment for the quality analysis of fire exits design.
\end{abstract}

Keywords: Emergency exits, Wayfinding, Human behaviour.

\section{INTRODUÇÃO}

Regulamentações com base no desempenho em segurança contra incêndio têm permitido a inserção de inovações tecnológicas tanto de sistemas de proteção passivas como ativas, e a introdução de soluções de projeto resultantes de estudos com auxílio de ferramentas computacionais. Incluem-se, nestas ferramentas, os simuladores de cenários 
de incêndio, de comportamento da estrutura à ação do calor ou de movimento de pessoas em situação de abandono (evacuação).

Existem, atualmente, dezenas de modelos computacionais de movimento de pessoas, que são a ferramenta mais básica para avaliação e aprimoramento do projeto de saídas de emergência, cada um com suas particularidades, potencialidades e limitações. Porém, o que se observa é que todos consideram, essencialmente, o movimento mecânico de fluxos de pessoas e alguns fatores comportamentais como a ação e reação de grupos familiares e de pessoas com diferentes níveis de familiaridade com o ambiente considerado. A influência da conformação espacial do ambiente construído em si e a percepção espacial dos usuários para as saídas de emergência ainda é pouco conhecida.

Por um lado, talvez esta característica dos modelos possa ser justificada pelo perfil dos pesquisadores e dos grupos de pesquisa envolvidos, não só no desenvolvimento dos softwares, mas, também, na área de projeto de segurança contra incêndio como um todo - essencialmente engenheiros, com pouca participação de arquitetos e de outras áreas do conhecimento mais diretamente envolvidas no estudo do comportamento humano, apesar de esforços, revelados em publicações como de Canter (1980) e eventos mais recentes e periódicos como o Symposium on Human Behariour in Fire (INTERSCIENCE COMMUNICATONS, 2012).

Tanto para o aprimoramento como para validação dos modelos, é fundamental a obtenção de dados de movimento de pessoas. Devido à dificuldade na obtenção de dados em situação de incêndios reais (evento raro), normalmente, recorre-se a dados de movimentação em locais públicos de grande concentração de público - o que permitiu o desenvolvimento de pesquisas como de Predtechsnkii; Milinskii (1978) e Fruin (1987) ou como dados coletados em experimentos ou treinamentos (simulados) de abandono de edifícios, como de Pauls (1980), pioneiramente.

No entanto, mesmo nestas situações, as questões relacionadas à influência da conformação espacial das rotas de fuga, assim como os meios para sua cognição e a relação com a qualidade arquitetônica dos espaços são pouco discutidas no âmbito da segurança contra incêndio, como pode ser visto em textos sobre saídas de emergência de pesquisadores consagrados como Pauls (2006); Tubbs e Meacham (2007); Bukowski (2009).

Desta forma, verifica-se a necessidade de estudos para compreensão da influência da arquitetura (a localização das saídas no pavimento, a conformação espacial das rotas de fuga para atingir uma saída segura, os componentes visuais e ambientais que influenciam nas decisões de caminhos a seguir, dentre outros) na eficácia das saídas de emergência, principalmente em edifícios grandes e complexos. O caminho contínuo entre um ponto qualquer de um pavimento até um local seguro fora da edificação, passando por corredores, passagens, portas, escadas, rampas, etc. deve ser passível de avaliação, por meio de parâmetros a serem propostos e analisados e que influenciam as soluções arquitetônicas para o ambiente construído.

De acordo com Arthur e Passini (1992), o wayfinding em edifícios complexos muitas vezes traz aos recém-chegados incertezas e estresse ao tentar estabelecer uma rota para atingir um determinado setor do edifício, fato que não incide tanto sobre os frequentadores familiarizados com o local.

A orientabilidade na circulação em edifícios complexos de multiplos pavimentos se reflete diretamente na qualidade das suas rotas de fuga. Além das dificuldades do wayfinding no plano horizontal para o encontro das saídas de emergência verticais (escadas), é necessário explorar as dificuldades encontradas durante o percurso vertical, 
sua relação cognitiva com o piso de descarga e, na sequência, com a saída para o exterior da edificação por meio de nova rota horizontal.

O presente estudo considera a circulação vertical na análise do wayfinding em edifícios de múltiplos pavimentos com foco nas saídas de emergência, considerando a orientação nos percursos dos usuários em relação ao acesso às rotas de fuga horizontais (corredores e passagens) e verticais (escadas).

Soeda et al. (1997) apud Holscher et al (2006) indentificaram que os sujeitos de experimentos de wayfinding em edifícios complexos de múltiplos pavimentos assumem que a topologia das plantas de diferentes pavimentos é idêntica, uma premissa que pode levar a dificuldades severas de wayfinding.

A finalidade da pesquisa é identificar as estratégias de wayfinding utilizadas por sujeitos para a orientação adequada com a finalidade de encontrar o local de destino estabelecido, bem como estudar métodos para relacionar o projeto arquitetônico à pesquisa de cognição espacial, melhorando a orientação em relação às rotas de fuga horizontais e verticais nos edifícios complexos. Neste contexto, este artigo apresenta uma discussão sobre os métodos 3D de análise de wayfinding com base nos resultados de experimentos exploratórios que são a base de um levantamento de dados maior.

\section{MÉTODOS E TÉCNICAS}

A grande maioria dos estudos experimentais de comportamento humano em wayfinding são baseadas na observação direta do comportamento do sujeito "navegador", segundo Holscher et al (2006). Este método de análise foi desenvolvido para pesquisas em wayfinding por Passini (1984), e se utiliza da descrição verbal do sujeito "navegador" como principal fonte de informações, sendo que este autor defendia como melhor estratégia a verbalização "concorrente" (concurrent verbalization), ou seja, a verbalização em tempo real, relatada ao longo da realização do experimento. Outro tipo de registro verbal muito usual é a verbalização retrospectiva (Ericsson e Simon (1993) apud Holscher et al (2006)), ou seja, relatada após a finalização da tarefa adotada neste experimento, numa sequência cronológica.

Os experimentos conduzidos no estudo-piloto apresentado neste trabalho não utilizou a verbalização concorrente, mas tem como base a observação direta do comportamento do sujeito, associada à verbalização retrospectiva, pela coleta de dados por meio de questionários semi-estruturados em dois tempos do experimento, ou seja, numa etapa intermediária e na etapa final do percurso estabelecido. Foram observados e registrados dados qualitativos como a distância percorrida, o tempo, as mudanças de direção, os momentos em que o sujeito solicitou informações verbais, etc.

\subsection{Os participantes}

Participaram do estudo-piloto seis voluntários, estudantes de graduação, sendo 2 estudantes de arquitetura, 3 estudantes de engenharia e um estudante em tecnologia de edificações. A idade média dos estudantes era de 21 anos, sendo 5 homens e 1 mulher. Nenhum dos participantes possuia familiaridade com o edifício.

\subsection{O edifício}

Para o estudo-piloto da pesquisa, foi selecionado um edifício hospitalar de especialidade (ortopedia e traumatologia) situado na cidade de São Paulo. O edifício foi construído na década de 1950, época em que as exigências de segurança contra incêndio praticamente inexistiam no país e sofreu pouca intervenção física no seu corpo principal, constituído 
originalmente das Alas A e B, mas recebeu três grandes ampliações, que são a Ala C, o Ambulatório e do Edifício Anexo (sobre o Ambulátório). O edifício de 10 pavimentos (subsolo, térreo e 8 pisos elevados) possui uma ampla escada central aberta que serve do subsolo ao $7^{\circ}$ andar e duas escadas laterais estreitas nas extremidades opostas das Alas $\mathrm{A}$ e $\mathrm{B}$, que servem do $1^{\circ}$ ao $8^{\circ}$ andar, ou seja, sem atingir o piso térreo (vide Figura 1).

\section{Figura 1 - Edifício hospitalar estudo-de-caso}

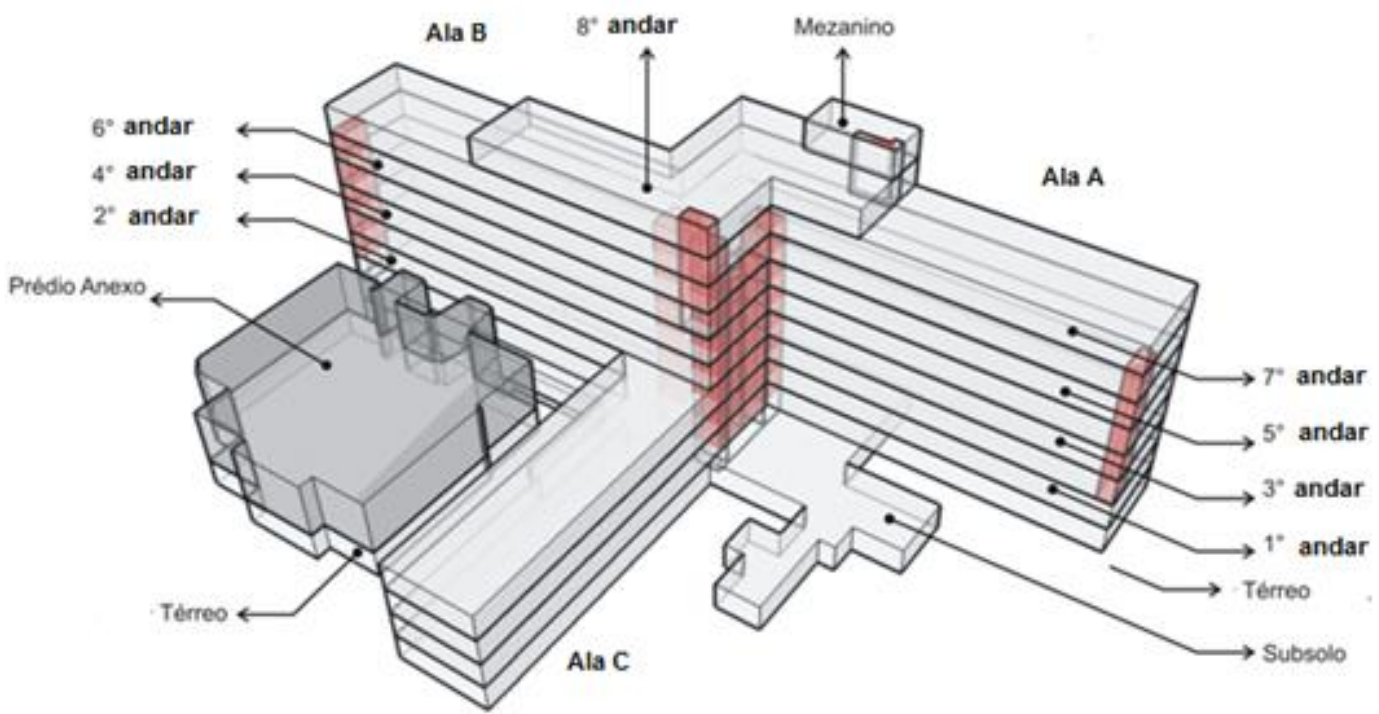

Fonte: Adaptado de ORNSTEIN et al (2007)

Numa análise prévia das características de wayfinding deste edifício, verificou-se que este apresenta uma grande deficiência na sinalização dos andares e, em alguns casos, das próprias salas que compõem cada pavimento. Não há nenhuma indicação do andar nos pavimentos e nem um mapa geral na entrada ou em cada andar para orientação dos visitantes. Na parte elevada do edifício não há nenhuma sinalização que identifique as duas grandes alas, denominadas A e B.

\subsection{Procedimentos}

Neste edifício, a atividade proposta para os voluntários era percorrer dois trechos e encontrar três pontos no interior do edifício. O primeiro trecho (A-B) do percurso tinha como finalidade possibilitar ao sujeito o reconhecimento de espaços do edifício até atingir um destino, colocando-o na posição de um visitante que entra pela primeira vez no hospital. O segundo trecho (B-E) incluía o acesso a uma saída de emergência vertical do andar (ponto C), a descida até o final da escada (ponto D) e o trajeto até um local seguro fora da edificação (ponto E).

Um balcão de informações situado no pavimento térreo foi estabelecido como ponto de partida (ponto A). Os sujeitos foram orientados a solicitar informações sobre a rota até o ponto B nesse balcão. Foram estipulados dois experimentos, com dois diferentes pontos B para diferentes sujeitos. Para uma parte dos participantes foi solicitado encontrar a biblioteca situada no $3^{\circ}$ andar (Experimento 01) e para a outra, o quarto B422- no $4^{\circ}$ andar (Experimento 02). Nesta etapa, os sujeitos foram informadosque poderiam utilizar os elevadores para o deslocamento vertical.

Um pesquisador permaneceu no ponto A para coordenar a partido dos sujeitos e no ponto "B" havia outro pesquisador que fornecia o questionário da primeira etapa do 
percurso para ser respondido e informava quanto ao segundo percurso, que seria do ponto "C" (encontrar uma saída descendente por meio de escadas), passando pelo ponto "D" (final da escada) e chegando ao ponto "E" (lado externo da edificação). Nesta etapa, foi informado que o elevador não poderia ser utilizado. No ponto "E" foi fornecido um segundo questionário, relacionado à segunda etapa do percurso. As Figuras 2, 3 e 4 apresentam a localização dos dois pontos "B", no $3^{\circ}$ e $4^{\circ}$ andares e os possíveis pontos "C" de acesso à escada vertical, assim como o ponto "E" e "A" no térreo.

O destino determinado para o experimento 01 apresentava as seguintes características:

a) $\mathrm{O}$ pavimento de destino ( $3^{\circ}$ andar) abriga em uma de suas alas, o setor administrativo do hospital e na outra, o setor acadêmico-científico. A biblioteca ocupa a sala no final do corredor da ala científica (ala B), porém não possuía nenhuma placa de identificação no corredor de acesso ou na porta de entrada;

b) Todos os elevadores disponíveis no térreo paravam no $3^{\circ}$ andar;

c) A escada mais próxima à Biblioteca não estava acessível, pois a porta de vidro que a separava do corredor estava trancada neste andar. Portanto, o local não oferecia a possibilidade de utilizar alternativas de saída de emergência além da escada principal (central).

Já o experimento 02 apresentava as seguintes condições:

a) O pavimento de destino ( $4^{\circ}$ andar) abriga, em suas duas alas, quartos de internação do hospital;

b) $\mathrm{O}$ elevador mais próximo à entrada do edifício (ponto A) só dava acesso ao $3^{\circ} \mathrm{e}$ $6^{\circ}$ andares (sinalizada na porta do andar do elevador e no interior da cabine);

c) As alas não estão identificadas, mas os quartos possuem identificação numérica na porta, sendo a letra $\mathrm{A}$ ou $\mathrm{B}$, referentes às respectivas alas, e os números consecutivos referentes aos quartos em numeração crescente a partir do acesso às alas pelo hall central, sendo que a unidade da centena se refere ao andar. Assim, o quarto B422 fica na ala $\mathrm{B}$ do $4^{\circ}$ andar;

d) A escada alternativa localizada no extremo do corredor da Ala B deste andar estava com a porta de vidro aberta, permitindo o seu acesso e uso como rota alternativa de fuga.

Figura 2 - Experimento 01 - Ponto B (Biblioteca) e possíveis pontos C (escadas) no $3^{\circ}$ andar.

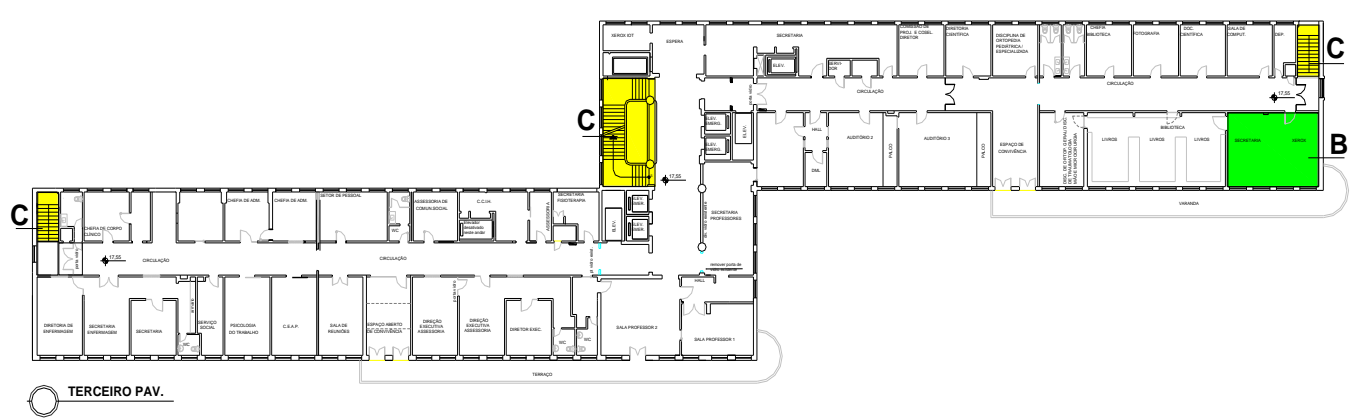


Figura 3 - Experimento 02 - Ponto B (Quarto B422) e possíveis pontos C (escadas) no $4^{\circ}$ andar.

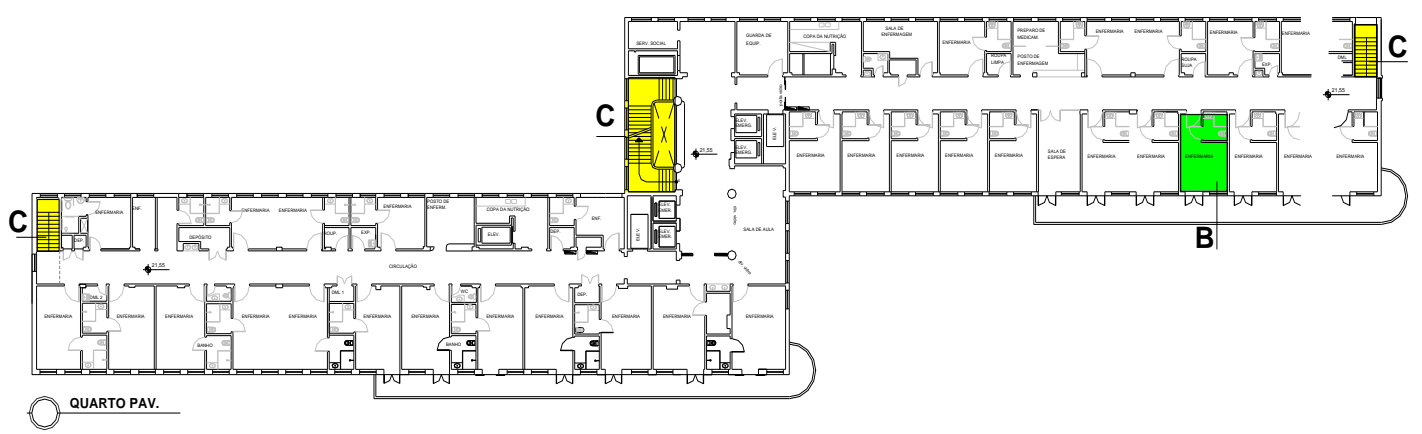

Figura 4 - Pavimento térreo com pontos A e D e possíveis pontos E.

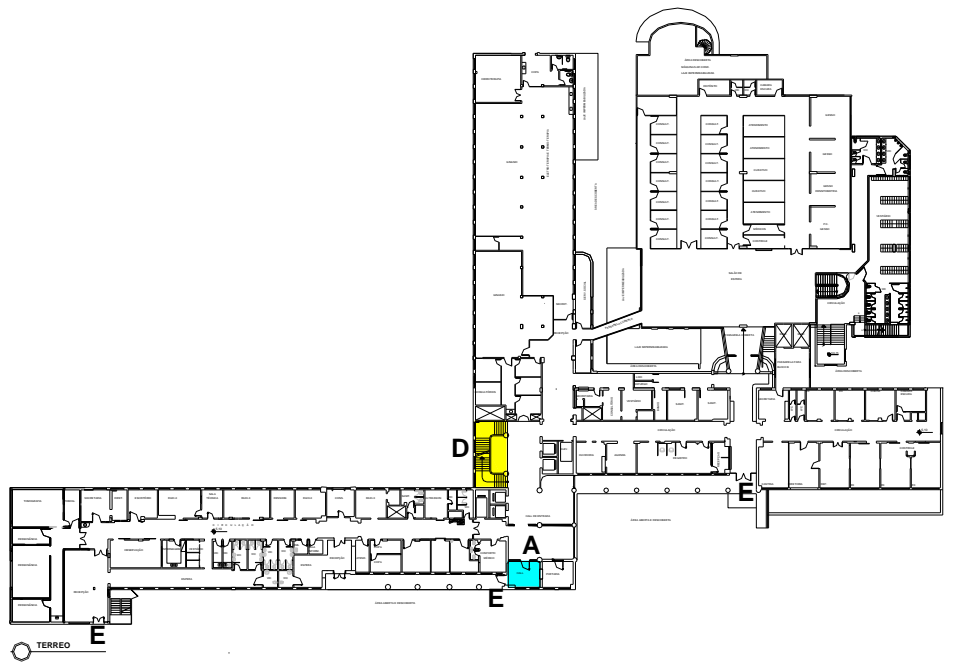

Foram utilizados dois tipos de minicâmeras para registrar os percursos, uma com a filmagem angular e outra com a filmagem tradicional. Cada voluntário fez seu percurso com a câmera angular na altura dos olhos. Em alguns casos, também foi feita a filmagem por uma segunda pessoa, que seguia a pessoa que fazia o trajeto, com a câmera tradicional. As diferentes situações são apresentadas no Quadro 1.

Para complementar os dados captados pelos registros de imagem, foram elaborados dois questionarios semi-estruturados. O primeiro questionário tratava de questões relativas à orientação dentro do edifício, com considerações sobre a estratégia adotada para o percurso realizado, os meios utilizados para orientação e a facilidade em encontrar o caminho até o ponto B. 


\section{Quadro 1 - As variações no estudo-piloto}

\begin{tabular}{|c|c|c|c|c|}
\hline Exp & Sujeito & Gênero & $\begin{array}{c}\text { Câmera no } \\
\text { sujeito }\end{array}$ & $\begin{array}{c}\text { Câmera de } \\
\text { acompanhamento }\end{array}$ \\
\hline \multirow{2}{*}{01} & 01 & Masculino & $\operatorname{sim}$ & não \\
\cline { 2 - 5 } & 02 & Masculino & $\operatorname{sim}$ & $\operatorname{sim}$ \\
\hline \multirow{4}{*}{02} & 03 & Masculino & $\operatorname{sim}$ & não \\
\cline { 2 - 5 } & 04 & Feminino & $\operatorname{sim}$ & $\operatorname{sim}$ \\
\cline { 2 - 5 } & $02 *$ & Masculino & $\operatorname{sim}$ & $\operatorname{sim}$ \\
\cline { 2 - 5 } & 05 & Masculino & $\operatorname{sim}$ & não \\
\cline { 2 - 5 } & 06 & Masculino & $\operatorname{sim}$ & não \\
\hline
\end{tabular}

(*) Sujeito que havia participado do experimento 01 anteriomente.

O segundo questionário tratava de questões relativas às rotas de fuga e escadas, com questões direcionadas especificamente à facilidade de encontrar a escada, à noções de orientação ao chegar ao final da escada e na saida para o exterior do edificío. $O$ questionário também incluiu considerações gerais sobre a percepção dos voluntários quanto as dificuldades do wayfinding, com base em estrutura de uma pesquisa anterior (PAUL, 2003).

Os participantes do estudo piloto não receberam informações ou as plantas da edificação, além daquelas fornecidas pelo recepcionista no ponto A e foram orientados a encontrar os pontos de destino, se possível, sem perguntar às pessoas que encontrava pelo caminho.

\subsection{Medições}

Previamente à realização dos experimentos, foram identificados os prováveis percursos entre todos os trechos considerados na pesquisa. Estes foram medidos e foi elaborada uma lista com as possíveis alternativas, desde a mais direta e curta até a mais rebuscada.

A proposta da pesquisa é a medição do desempenho no percurso por meio das seguintes variáveis, observadas nas filmagens: a) tempo para completar trechos do percurso; b) número de paradas; c) número de vezes que demonstrou clara perda de noção de localização; d) número de vezes que pediu informações adicionais a alguém.

\section{RESULTADOS E DISCUSSÃO}

Os tempos individuais medidos no Experimento 01, que contou com 2 sujeitos, são apresentados na Tabela 1. Após a realização do experimento 01 com esses dois sujeitos, passou-se para o experimento 02 , a fim de verificar a variabilidade ocasionada pelos diferentes destinos definidos na pesquisa, uma vez que o segundo experimento possibilitava alternativas de percurso tanto ao ponto B como ao ponto C. Os resultados do experimento 02 podem ser verificados na Tabela 2. Esta tabela suprime o Ponto C (escadas), uma vez nem todos os sujeitos realizaram o mesmo percurso ou utilizaram a mesma escada.

Na Tabela 2 é possível notar uma variação significativa entre os tempos dos sujeitos no Experimento 02, tanto no trecho A-B como no trecho B-D. Já no trecho D-E, que é curto e simples, verifica-se uma pequena variação nos tempos dos diferentes indivíduos. No Quadro 2, são apresentadas as observações do comportamento assim como das 
ações e dos movimentos realizados, obtidos com base na filmagem do percurso de cada sujeito, que justificam aos tempos apresentados.

Tabela 1 - Tempos individuais medidos no Experimento 01 (s)

\begin{tabular}{|c|c|c|c|c|c|}
\hline \multirow{2}{*}{ Sujeitos } & \multicolumn{5}{|c|}{ Trechos } \\
\cline { 2 - 6 } & A-B & B-C & C-D & D-E & Total \\
\hline 01 & 152 & 56 & 47 & 14 & 269 \\
\hline 02 & 174 & 40 & 61 & 19 & 294 \\
\hline
\end{tabular}

Tabela 2 - Tempos individuais medidos no Experimento 02 (s)

\begin{tabular}{|c|c|c|c|c|}
\hline \multirow{2}{*}{ Sujeitos } & \multicolumn{4}{|c|}{ Trechos } \\
\cline { 2 - 5 } & A-B & B-D & D-E & Total \\
\hline 03 & 120 & 59 & 17 & 196 \\
\hline 04 & 235 & 157 & 19 & 411 \\
\hline $02^{*}$ & 98 & 94 & 19 & 211 \\
\hline 05 & 166 & 84 & 15 & 265 \\
\hline 06 & 270 & 105 & 16 & 375 \\
\hline Média & 178 & 100 & 17,2 & 295 \\
\hline Desvio padrão & 74 & 36 & 1,8 & 100 \\
\hline
\end{tabular}

(*) Sujeito que havia participado do experimento 01 anteriomente.

Os tempos maiores de percurso do trecho A-B são de sujeitos que tiveram maior dificuldade de navegação, com paradas e clara demonstração de desorientação em alguns momentos. Observa-se que esses dois sujeitos também são os que levaram maior tempo para realizar o trecho B-D. Observa-se que os percursos realizados por esses dois sujeitos, tanto do trecho A-B como B-D, não são coincidentes.

Além disso, observou-se nas gravações, que a forma como os recepcionistas orientam os sujeitos variou muito e, em alguns casos, o próprio sujeito, ao solicitar informações, conseguiu obter melhor orientação que outros. Portanto, este também um fator a considerar em experimentos futuros.

Em relação aos questionários que foram aplicados após a conclusão dos trechos A-B e B-E, verificou-se a necessidade de alguns aprimoramentos estruturais, como a redução da escala de alternativas de respostas, originalmente de 6 e 10 graduações. As perguntas deveriam ser melhor agrupadas por tema e reduzidas em número. Alguns itens que constam da pesquisa de Paul (2003) aparentemente não foram relevantes para este estudo de caso específico, não agregando nenhum conteúdo aos resultados desta pesquisa (exemplo: influência da iluminação ou do ruído dos ambientes no wayfinding). 
Quadro 2 - Medidas e comportamentos observados por sujeito

\begin{tabular}{|c|c|c|c|c|}
\hline $\begin{array}{l}\text { Experi- } \\
\text { mento }\end{array}$ & Sujeito & \multicolumn{2}{|l|}{ Medidas } & Observações de comportamento \\
\hline \multirow{6}{*}{01} & \multirow{3}{*}{01} & Paradas (n) & 03 & \multirow{3}{*}{$\begin{array}{l}\text {-Recepcionista } 1: \text { " } 3^{\circ} \text { andar". } \\
\text {-Subiu direto de elevador, pediu informação no } \\
\text { hall central e desceu pela escada central. }\end{array}$} \\
\hline & & Pedido de informação (n) & 01 & \\
\hline & & Perda de noção espacial(n) & 01 & \\
\hline & \multirow{3}{*}{02} & Paradas (n) & 01 & \multirow{3}{*}{$\begin{array}{l}\text {-Recepcionista 1: " } 3^{\circ} \text { andar, } 1^{\circ} \text { elevador, Ala B } \\
\text { (apontando direção)". } \\
\text {-Obteve informações mais detalhadas na } \\
\text { recepção, subiu direto de elevador e desceu pela } \\
\text { escada central. }\end{array}$} \\
\hline & & Pedido de informação (n) & 02 & \\
\hline & & Perda de noção espacial(n) & - & \\
\hline \multirow{15}{*}{02} & \multirow{3}{*}{03} & Paradas (n) & 01 & \multirow{3}{*}{$\begin{array}{l}\text {-Recepcionista 1: "seguir corredor, elevadores } \\
\text { "de lá", Ala B". } \\
\text {-Obteve informação detalhada do percurso, subiu } \\
\text { direto de elevador e desceu pela escada mais } \\
\text { próxima (extremo da Ala B) até o } 1^{\circ} \text { andar e, } \\
\text { depois, pela escada central. }\end{array}$} \\
\hline & & Pedido de informação (n) & - & \\
\hline & & Perda de noção espacial(n) & - & \\
\hline & \multirow{3}{*}{04} & Paradas (n) & 02 & \multirow{3}{*}{$\begin{array}{l}\text {-Recepcionista } 2: \text { " } 4^{\circ} \text { andar, de elevador". } \\
\text {-Subiu direto de elevador e desceu pela escada } \\
\text { mais próxima até } 1 \text { o andar e, depois pela escada } \\
\text { central. } \\
\text { - Ficou desorientado /inseguro principalmente no } \\
\text { caminho do ponto A para o ponto B. Perguntou } \\
\text { direção no hall central e na enfermaria da ala B. }\end{array}$} \\
\hline & & Pedido de informação (n) & 02 & \\
\hline & & Perda de noção espacial(n) & 01 & \\
\hline & \multirow{3}{*}{$02 *$} & Paradas (n) & 01 & \multirow{3}{*}{$\begin{array}{l}\text {-Recepcionista } 2 \text { : "elevadores, } 4^{\circ} \text { andar". } \\
\text {-Subiu direto de elevador e desceu pela escada } \\
\text { central. Ignorou a possibilidade da escada mais } \\
\text { próxima (incorporou conhecimento anterior). }\end{array}$} \\
\hline & & Pedido de informação (n) & - & \\
\hline & & Perda de noção espacial(n) & - & \\
\hline & \multirow{3}{*}{05} & Paradas (n) & - & \multirow{3}{*}{$\begin{array}{l}\text {-Recepcionista } 3: \text { " } 4^{\circ} \text { andar, ala B". } \\
\text {-Pegou elevador que só parava no } 3^{\circ} \text { e } 6^{\circ} \text { andar, } \\
\text { percebeu o erro, desceu no } 3^{\circ} \text { e subiu } 1 \text { andar } \\
\text { pela escada central. Retornou pela escada mais } \\
\text { próxima até o } 1^{\circ} \text { andar e, depois, pela central. }\end{array}$} \\
\hline & & Pedido de informação (n) & - & \\
\hline & & Perda de noção espacial(n) & - & \\
\hline & \multirow{3}{*}{06} & Paradas (n) & 03 & \multirow{3}{*}{$\begin{array}{l}\text {-Recepcionista } 3: \text { " } 4^{\circ} \text { andar". } \\
\text {-Pegou elevador que só parava no } 3^{\circ} \text { e } 6^{\circ} \text { andar, } \\
\text { foi até o } 6^{\circ} \text {, voltou ao } 3^{\circ} \text {, percorreu toda a ala A } \\
\text { do } 3^{\circ} \text { e, depois, subiu } 1 \text { andar pela escada central. } \\
\text { Pediu informação no hall central, na entrada da } \\
\text { ala B. Retornou pela escada central. }\end{array}$} \\
\hline & & Pedido de informação (n) & 01 & \\
\hline & & Perda de noção espacial(n) & 02 & \\
\hline
\end{tabular}

(*) Sujeito 2 que já participou do experimento 01 anteriomente.

Verificou-se também que seria interessante incluir um item que requeresse uma avaliação global do processo de análise de wayfinding pelos sujeitos. As quatro últimas perguntas do $2^{\circ}$ questionário, de forma aberta, foram as que forneceram as informações mais relevantes, confirmando a deficiência geral de sinalização no edifício e, principalmente, a necessidade de sinalizar as Alas A e B nos pavimentos superiores.

\section{CONSIDERAÇÕES FINAIS}

Esta pesquisa exploratória permitirá a consolidação de procedimentos para a realização de uma pesquisa mais ampla contemplando uma população maior de sujeitos, com o aprimoramento de alguns itens relacionados à escolha dos edifícios estudo-de-caso, 
assim como dos destinos dos percursos, com o objetivo específico de avaliar a qualidade do projeto sob o ponto de vista das saídas de emergência.

\section{AGRADECIMENTOS}

Ao apoio do $\mathrm{CNPq}$ e do Instituto de Ortopedia e Traumatologia do Hospital das Clínicas da Faculdade de Medicina da Universidade de São Paulo à pesquisa.

\section{REFERÊNCIAS}

ARTHUR, P.; PASSINI, R. Wayfinding - People, Signs, and Architecture. New York: McGraw-Hill, 1992.

BUKOWSKI, R.W. Emergency Egress from Buildings (NIST Technical Note 1623), Gaithersburg: National Institute of Standards and Technology, 2009.

CANTER, D. (Editor). Fires and Human Behaviour. New York: John Wiley \& Sons, 1980.

FRUIN, J.J. Pedestrian Planning and Design (revised edition). Mobile: Elevator World, 1987.

HAO,J.,CHING CHIUAN,Y.. Wayfinding in Complex Multi-stoey Buildings:A vision simulation-augmented wayfinding protocol study. in: Undisciplined Design Research Society Conference 2008, Sheffield Hallan University, Sheffield, UK, 16-19 July 2008.

HAQ, S.,ZIMRING,C. Just down the road a piece: The development of topological knowledge of buildings layouts. Environmental and Behavior, vol.35 No.1 January p.132-160, 2003.<http://eab.sagpub.com/content/35/1/132>

HOLSCHER,C.; MEILINGER, T.;VRACHLIOTIS, G.; BROSAMLE, M.;KNAUFF, M. A. C. Up the down staircase:Wayfinding strategies in multi-level buildings. Jornal of Environmental Psychology 26 (2006), pg.184-199, Elsevier, 2006.

INTERSCIENCE COMMUNICATIONS. International symposium on human behaviour in fire, 5., 2012, Cambridge. Proceedings... London: Interscience Communications, 2012.

ORNSTEIN, S.W., ONO, R., LOPES, M.E., MONTEIRO, R.Z.; GILL, A.A; MACHRY, H.S. Healthcare Architecture in São Paulo, Brazil: Evaluation of Accessibility and Fire Safety in Large Hospitals. Archnet-IJAR: International Journal of Architectural Research. , v.1, p.13 - 25, 2007.

PASSINI, R. Wayfinding in Architecture. New York: John Wiley and Sons, 1984.

PAUL, M. Factors that influece ease of wayfinding in a hospital setting. 2003. Dissertation Faculty of the Graduate School at the University of Missouri-Columbia, Missouri, EUA.

PAULS, J. L. Building Evacuation: Research Findings and Recommendations. In: CANTER, D. (Ed.) Fires and Human Behaviour, New York: John Wiley and Sons, 1980, p. 251-275.

PAULS, J. L. The movement of people in buildings and design solutions for means of egress. Fire Technology, vol. 20, N. 1, p.27-47, 2006.

PREDTECHSNKII, V.M.; MILINSKII, A.I. Planning for Foot Traffic Flow in Buildings. New Delhi: Amerind Publishing, 1978.

TUBBS, J.S.; MEACHAM, B. J. Egress Design Solutions - A Guide to Evacuation and Crowd Management Planning. New Jersey: John Wiley and Sons, 2007. 